\title{
Evidence-based prevention of cannabis use in Flanders \\ Is there a role for health economic evaluation?
}

by

\author{
Matthys $\mathrm{N}^{1}$, Van Hal $\mathrm{G}^{1}$, Beutels $\mathrm{P}^{1}$
}

\begin{abstract}
Objectives

Cannabis is a popular drug in Flanders, in spite of the fact that the prevention of its use lists high on the Flemish political agenda. The Flemish Government aims to prevent cannabis use efficiently and in achieving this, a health economic analysis could be helpful. The possibilities and limitations of applying economic evaluation techniques to the prevention of substance (ab)use, are discussed in this paper.
\end{abstract}

Methods

A thorough literature search, interviews with key persons, an internet search and an analysis of unpublished reports and documents was performed.

Results

The interrelation between various forms of substance use, and of the array of strategies to prevent this (including the costs thereof), seems to demand a joint evaluation of multiple substances.

\section{Conclusions}

More than methodological difficulties, the general lack of knowledge on age- and timespecific health and income effects caused by various forms of substance (ab)use, currently makes the evidence-based evaluation of prevention of cannabis use in Flanders a virtually impossible undertaking.

\section{Keywords}

Belgium, cannabis, evidence-based medicine, medical economics, prevention, programme effectiveness

\footnotetext{
Epidemiology and Social Medicine, University of Antwerp, Antwerp, Belgium guido.vanhal@ua.ac.be
} 


\section{Introduction}

In Europe, cannabis is the most commonly used illegal drug (1). This is also the case in the Flemish Region of Belgium. The latest surveys reveal that about one fourth to one third of 15- to 16-year-old Flemish school students have ever used cannabis (2-4). In Flemish university and college students, one out of two has ever used cannabis (5). The lifetime experience in the general population is assessed through the 'National Health Survey' (6). This survey indicates that $12.0 \%$ of adults (aged 15 to 64 years) have tried the substance at least once (lifetime use). Recent use (in the last 12 months) was reported by $4.6 \%$ and use in the last month was reported by $2.6 \%$ of all adults (aged 15 to 64 years).

Still, as in most countries, cannabis is illegal in Belgium. In addition, cannabis use can cause adverse health effects. Therefore, prevention of drug use in general and cannabis in particular, lists high on the Belgian political agenda.

At the federal level, illegal drug (ab)use focuses mainly on legislation and control, i.e. the prevention of crime.

The regions in Belgium (Flanders, Wallonia and Brussels) have autonomy over the choice and design of prevention strategies that improve population health. At the Flemish level, (drug) prevention policy aims to maximise health gains on the population level. Therefore, the Flemish Government stimulates drug prevention workers to use evidence based approaches. However, interpretation of what constitutes evidence-based prevention is highly variable. We define it here as follows: evidence-based prevention means that it can be shown to prevent ill health and to improve good health. In the current article, we review how such evidence can be compiled and analysed for the optimal prevention of cannabis (ab)use, and which evidence is already available. In doing this, the focus is on the possible identification of strategies that maximise health gains for a given budget constraint. Therefore, we explore the possibilities for health economic evaluations to help making decisions in the area of drug prevention.

\section{Methods}

This article is based on a recent study by the authors (7). Several qualitative research methods were applied in this study.

First, a literature review was accomplished. Databases were searched for the following key terms: (illicit) drugs, drug (mis)use, drug abuse, substance (mis)use, substance abuse and cannabis, in combination with prevention, evidence(-)based, science(-)based, effectiveness, (effect)evaluation, cost-effectiveness, health, Belgium and Flanders. The electronic search concentrated on the following databases: Medline, PubMed and Sociological Abstracts.

Second, experts were consulted on (the evaluation of) prevention of cannabis use: semistructured interviews were conducted with drug prevention workers, the persons in charge of drug prevention programmes and drug prevention experts. 
Third, we attempted to access the grey literature (unpublished articles and documents).

Fourth, relevant websites were identified, mainly by using the search engine Google.

\section{Position in the evidence based debate}

As previously mentioned, interpretation of what constitutes evidence-based prevention of drug use is highly variable. This fits into the discussion about evidence-based health promotion, which is made elsewhere (8-14).

It comes down to the fact that, concerning health promotion, no consensus about 'evidence', and how to obtain it, exists. Some, in this case the Flemish policy makers, demand epidemiological indicators to demonstrate the effects of health promotion. Effects should be expressed in terms of quantitative health outcomes on the population level, e.g. morbidity, mortality and quality adjusted life years (QALYs), which are measures frequently used in biomedical sciences. However, health promotion workers deem this to be impossible. The methods used in biomedical sciences imply that identifiable cause-effect relations are investigated. Health promotion operates in a complex context, where numerous social, economic, political, and cultural factors interact. Therefore, causality generally cannot directly be assessed. Although some alternative methods have been proposed for the health promotion field, all of these would need further development in order to be helpful for allocative policy decisions.

The perspective of our paper uses as a starting point the approach of the Flemish Government: 'evidence' of the effectiveness of drug (ab)use prevention in general and cannabis in particular, should be expressed in terms of quantitative health outcomes on the population level. We explore here the limits of traditional quantitative analysis for the prevention of cannabis, as it is now traditionally used for policy in biomedical sciences.

\section{What evidence is needed?}

To this day, in Flanders mainly qualitative evaluation research of drug use prevention is accomplished. Some evaluative questions that are typically used to do this are given in table 1 .

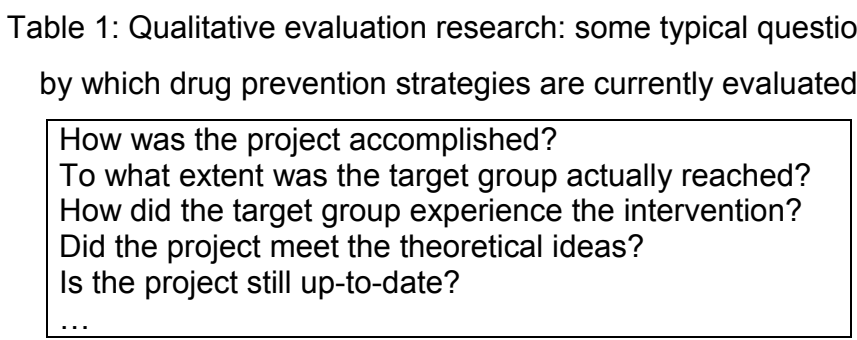

Such evaluations are relevant for the programme makers themselves, because they can demonstrate why an effect has or has not occurred. However, those studies do not give any information about the effects in terms of health gains. Therefore, this kind of research is less relevant for the Flemish policy makers: in their opinion no 'evidence' is gathered. 
Potential quantitative health outcomes to express the population effectiveness of interventions against drug (ab)use are:

- decrease in the number of problem users

- decrease in the period of time (ab)users remain (ab)users

- decrease in morbidity related to drug (ab)use

- decrease in mortality related to drug (ab)use

Concerning the evaluation of prevention of cannabis (ab)use, mainly 1, 2, and 3 are relevant, because this kind of drug use is very unlikely to have an impact on mortality. Note that these quantitative outcomes are not independent, because clearly 3 and 4 are influenced by 1 and 2. Furthermore, 3 and 4 combined can be expressed as increases in Quality Adjusted LifeYears (QALYS), which has become one of the main expressions of aggregated health outcomes in economic evaluation.

More specifically, the information necessary to evaluate the effectiveness of drug use prevention on a population level can be found in table 2 .

Table 2: Data required for health related evaluation of drug use prevention

\begin{tabular}{ll|}
\hline Effectiveness of the options for prevention in terms of \\
$-\quad$ Reducing the use of drugs \\
$-\quad$ Delaying the onset of first use \\
\hline Age and sex specific mortality and morbidity as a consequence of use \\
Age specific health effects (morbidity and mortality) as a consequence of (different levels of) use \\
$-\quad$ Age and sex specific prevalence and incidence of use \\
$-\quad$ Age and sex specific life expectancy, all causes and drug related \\
\hline
\end{tabular}

In addition, the information that is needed to expand effectiveness evaluations to health economic evaluations (e.g. to estimate cost-effectiveness) is presented in table 3 .

Table 3: Data health economic evaluation of drug use prevention would require, in addition to table 2

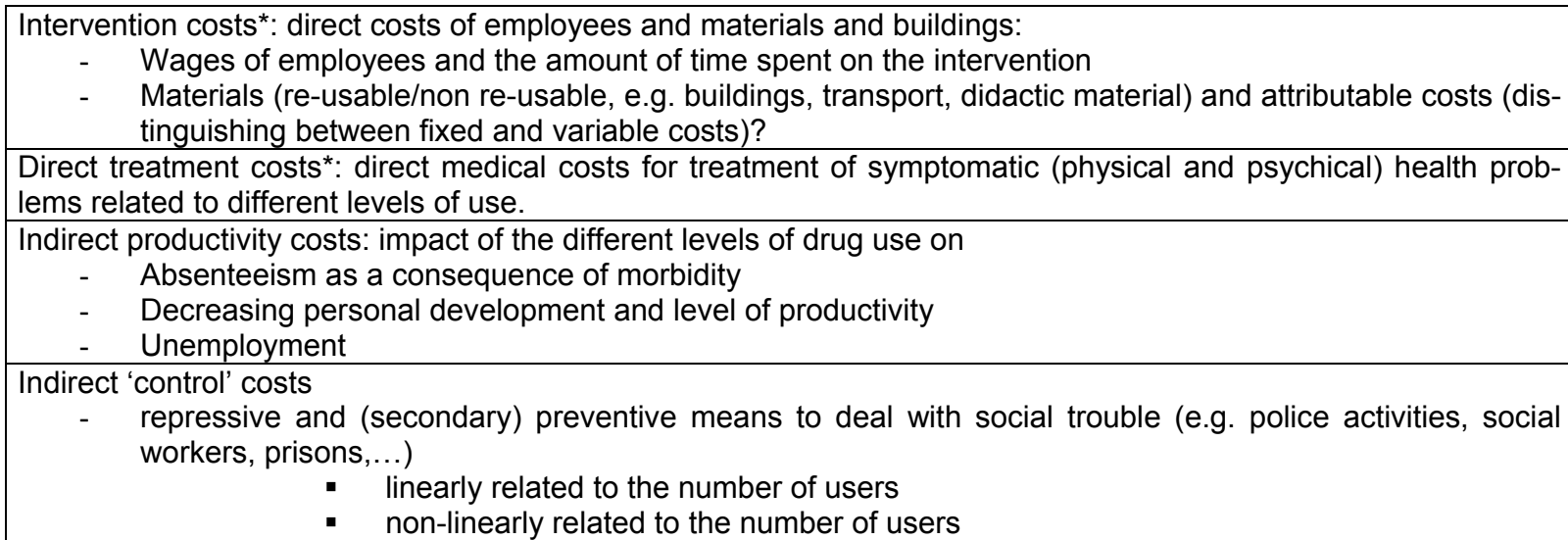

${ }^{*}$ Absolute minimally required data 


\section{(Obtain) the evidence}

This section documents what we know, and how we can assess what we don't know (yet) to apply effectiveness and cost-effectiveness analyses to this field.

Effectiveness of interventions for the prevention of cannabis use

Current state of the evidence: what do we know?

Several studies examining the effects of prevention programmes for the prevention of illicit substance use are conducted. Many researchers have tried to unite, compare and analyse the results of these evaluations in meta-analyses and overviews (15-30). The Health Development Agency (HDA - now the National Institute for Health and Clinical Excellence, NICE) of the United Kingdom has published an overview of reviews in 2004 (31). Because the amount of overviews is expanding, this publication was recently updated (32).

It is beyond the scope of this article to present the results of all these studies and overviews. Only the main conclusions will be outlined. Before doing so, however, some points should be noted. First of all, research examining or describing preventive interventions aimed only at cannabis use is very scarce, if not absent (33). Besides, there is a general lack of European evaluated prevention programmes. Therefore, basically all meta-analyses and overviews of prevention programmes draw predominantly on programmes from outside Europe, mainly from the US (33-35). Further, school-based preventive interventions have been examined most extensively, because most preventive interventions against drug abuse are directed at young persons $(19,35-36)$. Moreover, the effects are mainly expressed in terms of knowledge, attitudes toward drugs and use of drugs. Few studies, if any, examine whether it is possible to reduce the number of new cases of problematic drug use (according to the DSMIV diagnostic criteria) or whether interventions can prevent hard drug abuse in cannabis users (37).

In sum, studies have shown that school-based drug prevention programmes have the potential to reduce drug use in adolescents. For instance the meta-analysis conducted by Tobler et al. (2000) (28) has shown that interactive programmes result in significant reductions of drug use, while non-interactive ones do not. Non-interactive programmes are, in contrast to interactive programmes, structured, focused on didactic presentations by the teacher and do not focus on interactions between students.

Drug prevention programmes directed at other sectors or target groups have not been subjected to sufficient research to conclude whether they reduce drug (mis)use or not. Nevertheless, several interventions directed at other sectors than the school sector seem promising and may be able to reduce drug use and misuse (37-38). Clearly, more research is needed to document this. 


\section{General problems encountered in evaluating drug prevention}

There is a lack of European quantitative studies of drug use prevention. This can be explained by various types of research problems of practical, judicial, ethical and, methodological nature. Table 4 presents several examples of these.

Table 4: Overview of problems encountered for drug prevention evaluations

\begin{tabular}{|c|c|}
\hline \multicolumn{2}{|c|}{ ractical problems } \\
\hline 0 & $\begin{array}{l}\text { An intervention can induce different effects when it is implemented in different situations ( } \\
\text { schools), because the quality and context of the implementation determines its effectivenes } \\
\text { sequence, it is very difficult to estimate the overall effectiveness of preventive interventions. } \\
\text { Lack of financial sources } \\
\text { Lack of expertise } \\
\text { Lack of mandates and orders that encourage effect evaluations }\end{array}$ \\
\hline \multicolumn{2}{|r|}{$\begin{array}{l}\text { Judicial problem } \\
\text { Cannabis is an illegal drug in most countries, and self-reporting is often the only way to gather information on fre- } \\
\text { quency of (ab)use. The validity of self-reported data may be questionable. }\end{array}$} \\
\hline & problem \\
\hline
\end{tabular}

\section{Methodological problems}

An overview of methodological problems encountered in evaluating primary drug prevention, is presented by Uhl $(1998,2000)$. It goes beyond the scope of this article to give an extensive summary. Some of the main aspects are:

- $\quad$ The interest goes primary to long term effects of prevention. However, this kind of research is difficult to accomplish (amongst other things, there are problems to follow up participants over many years).

- $\quad$ Simultaneous influences: people are confronted with the drug topic in many different ways (e.g. media, courses, family, friends,...). Because of this, it is nearly impossible to separate intervention induced effects from effects caused through other influences.

- Dependence of observational units: a central, implicit assumption behind many statistical procedures is independency of observations. In drug prevention evaluation research it is common that the observational units are sampled in clusters or groups (e.g. school classes) and treated as independent units. The violation of this assumption may result in an increased rate of significance by mere chance.

\section{Possibilities for "classic" medical effectiveness evaluation methods}

The problems listed in table 4 indicate that gathering evidence on effectiveness of drug use prevention (and particularly for cannabis use) is not easy.

There are different epidemiological evaluation methods to evaluate drug use prevention. The classification of clinical research by Grimes and Schulz (2002) (39) gives a synoptic overview of the different types of study design:

"Clinical research falls into two general categories: experimental and observational, based on whether the investigator assigns the exposures or not. Experimental trials can also be subdivided into two: randomised and non-randomised. Observational studies can be either analytical or descriptive. Analytical studies feature a comparison (control) group, whereas 
descriptive studies do not. Within analytical studies, cohort studies track people forward in time from exposure to outcome. By contrast, case-control studies work in reverse, tracing back from outcome to exposure. Cross-sectional studies are like a snapshot, which measures both exposure and outcome at one time point. Descriptive studies, such as case-series reports, do not have a comparison group. Thus, in this type of study, investigators cannot examine associations, a fact often forgotten or ignored".

Because the main problems that researchers encounter in evaluating drug prevention are already mentioned above and in table 4, attention will only be drawn in short to some additional problems and possibilities, regardless.

\section{Experimental studies}

RCT has become the 'gold standard' for evidence based medicine (40-41). However, RCTs are difficult to accommodate the complexity of drug preventive interventions. Rychetnik et al. (2002) (12) postulate that RCTs can be designed to evaluate complex public health intervention, notably cluster RCTs (communities, schools or other clusters are the unit of analysis). But even they mention that this kind of research is often not feasible, because of practical or resource constraints. As an alternative, a non-randomised controlled trial can be accomplished. However, this study design also has some weaknesses, such as a selection bias and the fact that it raises ethical questions.

Observational studies

To evaluate a drug preventive intervention, a cohort study or a case-control study can be planned. For example, if one school implements a specific intervention, and another does not, a cohort study can be set up to follow the students of these two schools over several years. But, even if differences in drug use between the students of these two schools are found, one cannot be sure that this can be attributed to whether the students underwent the intervention or not.

Alternatively, a case-control study could be set up. In short, persons who (have) use(d) cannabis need to be found, and matched with persons who have never used cannabis. Subsequently, these participants could be questioned retrospectively about factors that may have been relevant for their decision to use or not use cannabis (e.g. being exposed to a specific drug preventive intervention). This approach also has some weaknesses, such as recall bias (depending mainly on how much time has elapsed since influential factors occurred), the existence of unknown decisive factors (which are therefore not part of the retrospective questioning), and the fact that the causality of associations cannot be proven.

(Age and sex specific) Adverse health effects of cannabis use (morbidity and mortality)

Current state of the evidence: what do we know?

Here, we will present a brief summary of the known adverse health effects of cannabis use. 
Concerning probable adverse health effects, there is no known fatal dose of cannabis, and no death has ever been attributed solely to the use of cannabis (42). Acute cannabis use can induce anxiety and panic, and moreover an acute psychosis (43-46). Additionally, cannabis use may cause cognitive and psychomotor impairment, which in turn leads to an increased risk of accidental injury or death if an intoxicated person attempts to perform complex tasks (e.g. driving a car) $(42,46-49)$.

The major adverse effects of chronic use are probably respiratory diseases associated with smoking as the method of administration (such as chronic bronchitis and respiratory tract cancers) (45-46, 50-51). Individuals with cardiovascular diseases are at an increased risk of precipitating or exacerbating the symptoms of their disease $(46,52)$. Furthermore, it is now recognised that cannabis use can lead to cannabis dependence, characterised by an inability to abstain from or to control cannabis use (45-46).

Finally, there is an association between cannabis use and some psychiatric illnesses (such as schizophrenia and depression), but whether there are causal relationships is unclear (45$46,50)$.

\section{Problems encountered in evaluating health effects of cannabis use}

To express the effects of cannabis use prevention in terms of health effects on a population level, more knowledge about the adverse health effects of cannabis use is required. Yet, there are several factors that contribute to the lack of knowledge.

First of all, research about the health effects of cannabis is, certainly compared to tobacco, a young research area and it takes several decades before the necessary clinical observations are available for conclusions to be drawn (46). And long-term research is essential for this health issue.

Second, there are difficulties in quantifying the degree of exposure to cannabis. Related to this, it is not (yet) clear to what extent the potency of cannabis (as indexed by $\Delta^{9}$-tetrahydrocannabinol (THC) content), contributes to the health effects. It has been claimed recently that the existing medical literature on the health effects underestimates its adverse health effects because it was based upon research conducted on less potent forms of cannabis than those that are available today. However, at present there is dearth of conclusive scientific information about the evolution of THC potency in cannabis over the last two decades in Europe in general and Flanders in particular, to draw any definite conclusions on this matter (53-54).

Third, there are interpretative problems. Alternative explanations (including other drug use) of associations between cannabis use and adverse health outcomes, are difficult to exclude.

\section{Possibilities for "classic" medical efficacy evaluation methods}

More research is needed to make conclusive judgements about the health effects of cannabis use. Can clinical research methods be used to provide the necessary scientific evidence?

Experimental studies 
Using RCTs to measure the health effects of cannabis use implicates that the experimental group is obliged to use this drug. It may be clear that, because of legal, ethical and practical reasons, this is not feasible. One can alternatively accomplish a non-randomised trial. In this case, participants choose themselves if they will or will not use cannabis. Yet, a selection bias will occur due to this self-selection. Furthermore, only short-term effects can be measured during the typical follow-up periods in this type of study.

Observational studies

On the one hand, to investigate the relation between cannabis use and adverse health effects in general, a cohort study can be set up. It must be noted, that this will take a long time and it needs good follow up of the participants, which will be expensive. Moreover, there can be a selection bias because the participants choose themselves if they use cannabis or not.

On the other hand, in order to investigate if a specific health outcome is caused by cannabis use, a case-control study can be undertaken. Patients are then entered into the study based on the presence or absence of the disease of interest. These two groups (one with, and one without the disease) are then compared to determine if they differ with regard to their exposure to cannabis. This kind of study often requires less time, money, and effort than another study design, and still could yield important scientific findings. Yet, case-control studies are also more susceptible to biases than other comparative studies (55). To provide useful and reliable results, case-control studies must be well designed and carefully executed. The selection of case and control groups, and measurement of exposure information are of great importance. Nonetheless, in this context, they seem the most feasible approach.

Prevalence and incidence of cannabis use

Age-specific prevalence and incidence of cannabis use can be investigated through crosssectional studies (i.e. quantitative surveys on a representative population sample). In many countries, including Belgium, the regular national health surveys could collect this information. The latest version of this survey (2004) (6) contains several questions on cannabis use (life time use, recent use, age at first use, frequency of use), but more aspects of cannabis use than only those surveyed at this moment are important (e.g. the amount of cannabis used per session/week/month).

The 2004 survey indicates that, in Flanders, 12.0\% of adults (aged 15 to 64 years) have tried the substance at least once (lifetime use) and $4.6 \%$ reported recent use (in the last 12 months). Use in the last month was reported by $2.6 \%$ of all adults (aged 15 to 64 years). Life time use, recent use, use in the last month and frequent use was reported more by males than females, and more by the younger than by the older age groups (6).

Furthermore, surveys about drug use among school populations are common in Belgium. As previously mentioned, the latest surveys reveal that about one fourth to one third of 15- to 16-year-old Flemish school students have ever used cannabis (2-4) and in Flemish university 
and college students, one out of two has ever used cannabis (5). Cannabis use is more common in boys versus girls, and in older versus younger students.

Until this day, information about prevalence and incidence of cannabis use is only based on self-reports. Although the use of cannabis will be admitted easier than the use of so-called hard drugs (56), other analytical methods would be more preferable, but due to ethical, legal and practical (blood and urine testing for cannabinoids is not yet quite perfect or socially acceptable) problems, this seems not that feasible today.

Life expectancy and mortality, all causes and related to cannabis use

General information about age-specific mortality and life expectancy are readily available (e.g. for Belgium, see http://statbel.fgov.be/). The causes of mortality in Belgium can be found in the 'Nationale Databank Mortaliteit' (National Database Mortality), but caution is needed when interpreting this information, due to likely miscoding (57). Besides, the definition of 'drug related death' does not include all deaths caused by drug use. For example, deaths caused by lung cancer, which in turn may partially be caused by smoking cannabis, are not recognised as drug related. It should be noted again though, that there is no known fatal dose of cannabis, and no death has ever been attributed solely to the use of cannabis. For these reasons, it is difficult, if not impossible, to express the effects of prevention of cannabis use in terms of mortality measurements.

\section{Intervention costs}

To map out the direct costs of personnel and material, a process evaluation will be necessary (58). In doing so, resource use will fall into two parts, namely volume (time, manpower, allocated fixed costs and the like) and price (cost per attributable unit of volume).

More specifically, the coordinators and/or the staff members of the intervention programme should be asked for information about the issues mentioned in table 3 , and documents, relevant to the cost structure of these interventions should be studied.

Considering the nature of most drug prevention interventions, it will be almost impossible to assign the prevention costs to one specific drug. It is difficult, if not impossible, to disentangle specific prevention efforts of cannabis use from interventions that, among other things, try to prevent or reduce cannabis use.

\section{Direct treatment costs}

Direct treatment costs can be obtained through surveys questioning workers in the health care sector and patients, and probably also in several databases (e.g. databases of the Rijksinstituut voor ziekte- en invaliditeitsverzekering [RIZIV, the National Institute for Health and Disability Insurance] or the Sickness Funds). However, it needs to be noted that Belgium trails behind in making publicly available anonymous information with regard to the costs for specific treatments. This arrear is caused by the fragmented character of the Belgian health 
care sector and the budget administrators, as well as competition between sickness funds, which provide (mandatory basic and additional) health insurance (59).

Indirect productivity costs

Indirect productivity costs also fall into two parts: the volume and price component. On the basis of the average gross labour costs, the price component can be calculated. The volume component, however, is more problematic. After all, drug use may not only be associated with absenteeism and unemployment, but also with decreasing productivity on the job. This kind of information could potentially be obtained in a large case-control study.

Indirect 'control' costs

On the basis of information about budgets for public safety and crime control, estimates of the percentage of social disruptions and troubles caused by drug users (and due to their drug use), these costs could be estimated. However, assigning these costs to a specific drug, in this case cannabis, will be problematic.

\section{Conclusion and discussion}

This article outlines which information would be theoretically needed to make an analysis of the impact of the prevention of drug use (and specifically cannabis use) in terms of health effects and economic costs. The perspective of policy makers (and specifically the Flemish Government) was taken as a starting point, because this specific question was actually asked by them. Their objective is to allocate available sources effectively and efficiently for the prevention of cannabis use. The legitimacy of this question is almost self-evident but the provision of science-based answers to its solution is shown here to be far less evident.

This article indicates the lack of knowledge on different aspects related to this policy question. Notably, more information is needed on the adverse health effects of cannabis use, the effects of drug prevention in terms of reducing cannabis use, delaying the onset of first use and decreasing the transition from 'soft' to 'hard', the age and sex specific prevalence and incidence of use, and different kinds of costs (intervention costs, direct treatment costs, indirect productivity costs and indirect control costs). In fact, also the positive effects of cannabis use should be taken into account (e.g. feeling and performing better, not using 'stronger' drugs). However, many problems hamper gathering all this information. As a consequence, it will be very difficult, if not impossible, to ever accomplish a credible health economic evaluation of cannabis prevention.

Although we wanted to steer away from the evidence-based discussion about drug prevention in particular, and health promotion in general, it seems unavoidable. We can no longer hold on to the definition of evidence that is postulated here, namely that the 'evidence' of the effectiveness of the prevention of drugs in general and cannabis in particular, should be expressed in terms of quantitative health outcomes on the population level. So, since many of the current methodologies seem ill-suited to evaluating cannabis use prevention programmes 
on the one hand but it is increasingly expected that health economic evaluations are carried out on the other hand, innovative, yet rigorous methods of evaluation need to be developed.

This article is, in fact, a contribution to the evidence-based debate. It shows the difficulties that one encounters when the perspective of (Flemish) policy makers is followed. Policy makers need to become aware of these difficulties, and need to acquire the perspective of most health promotion makers. More specifically, the search for alternative evaluation methods of health promotion in general, and drug prevention in particular, needs to increase in scope and substance.

\section{Acknowledgements}

We thank the Flemish Government for the financial support.

\section{References}

1. EMCDDA. Annual Report 2005. The state of the drugs problem in Europe. Luxemburg: Office for the Official Publications of the European Communities; 2005

2. Hibell B, Andersson B, Bjarnason T, Ahlström S, Balkireva O, Kokkevi A, Morgan M. The ESPAD Report 2003. Alcohol and other drug use among students in 35 European countries. Stockholm: The Swedish Council for Information on Alcohol and other Drugs, The Pompidou Group at the Council of Europe; 2004

3. Kinable H. Bevraging van Vlaamse leerlingen in het kader van een Drugbeleid Op School (Inquiry among Flemish pupils within the scope of Drug Policy at School). Brussel: VAD; 2006

4. Vereecken C, Maes L. Rapport jongeren en gezondheid. 1990-2002 (Report youth and health. 19902002). Gent: Universiteit Gent; 2002

5. Van Hal G, Rosiers J, Bernaert I, Bogaert E, Keersmaekers R. The higher they get... A survey on substance use among university and college students in Antwerp. European Society for Social Drug Research, $16^{\text {th }}$ annual conference 2005, Manchester, October 2005

6. Bayingana K, Demarest S, Gisle L, Hesse E, Miermans PJ, Tafforeau J, Van der Heyden J. Gezondheidsenquête door middel van interview, België, 2004 (Health interview survey, Belgium, 2004). Depotnummer: D/2006/2505/4, IPH/EPI REPORTS № 2006 - 035. Brussel: Wetenschappelijk Instituut Volksgezondheid, Afdeling Epidemiologie. $2006 . \quad$ Available at: http://www.iph.fgov.be/epidemio/epinl/crospnl/hisnl/table01.htm. Accessed February 2, 2006

7. Matthys N, Van Hal G, Beutels P. Evidence based cannabispreventie in Vlaanderen. Een overzicht van preventiestrategieën en mogelijkheden tot gezondheidsgerelateerde evaluatie op bevolkingsniveau (Evidence Based Prevention of Cannabis Use in Flanders. Overview of Prevention Strategies and Possibilities of Health Related Evaluation on Population Level). Antwerpen: Universiteit Antwerpen/Universitair Wetenschappelijk instituut voor Drugproblemen; 2006

8. Koelen MA, Vaandrager L, Colomér $\mathrm{C}$. Health promotion research: dilemmas and challenges. J Epidemiol Community Health 2001; 55: 257-62

9. McQueen DV, Anderson LM. What counts as evidence: issues and debates. In: Rootman I, Goodstadt M, Hyndman B, McQueen DV, Potvin L, Springett J, Ziglio E, editors. Evaluation in health promotion. Principles and perspectives. Copenhagen: WHO Europe; 2001. p. 63-79

10. McQueen DV. Strengthening the evidence base for health promotion. Health Promot Int 2001; 16: 261-8

11. McQueen DV. The evidence debate. J Epidemiol Community Health 2002; 56: 83-4

12. Rychetnik L, Wise M. Advocating evidence-based health promotion: reflections and a way forward. Health Promot Int 2004; 19: 247-57 
13. Saan $\mathrm{H}$, de Haes W. Gezond effect bevorderen : het organiseren van effectieve gezondheidsbevordering (Promoting healthy effects: the organisation of effective health promotion). Woerden: Nationaal Instituut voor Gezondheidsbevordering en Ziektepreventie; 2005

14. Tang KC, Ehsani JP, McQueen DV. Evidence based health promotion: recollections, reflections, and reconsiderations. J Epidemiol Community Health 2003; 57: 841-3

15. Allott R, Paxton R, Leonard R. Drug education: a review of British Government policy and evidence of effectiveness. Health Educ Res: Theory and Practice 1999; 14(4): 491-505

16. Belcher HM, Shinitzky HE. Substance abuse in children. Arch Pediatr Adolesc Med 1998; 152(10): 95260

17. Black DR, Tobler NS, Sciacca JP. Peer helping/involvement: an efficacious way to meet the challenge of reducing alcohol, tobacco, and other drug use among youth? J Sch Health 1998; 68(3): 87-93

18. Botvin GJ. Adolescent drugs abuse prevention: current findings and future directions. In: Glantz MD, Hartel CR, editors. Drug abuse: origins and interventions. Washington DC: American Psychological Association; 1999a. p. 285-308

19. Botvin GJ. Prevention in schools. In: Ammerman RT, Ott P, editors. Prevention and societal impact of drug and alcohol abuse. Mahwah, NJ: Lawrence Erlbaum Association; 1999b. p. 281-306

20. Botvin GJ. Preventing drug abuse in schools: social and competence enhancement approaches targeting individual-level etiologic factors. Addict Behav 2000; 25(6): 887-97

21. Coggans N, Cheyne B, McKellar S. The life skills training drug education programme: a review of research. Scottish Executive Effective Interventions Unit, Scottish Executive Drug Misuse Research Programme. Scotland: University of Strathclyde; 2003

22. Dusenbury L, Falco M, Lake A. A review of the evaluation of 47 drug abuse prevention curricula available nationally. J Sch Health 1997; 67(4): 127-32

23. Flay BR. Approaches to substance use prevention utilising school curriculum plus social environment change. Addict Behav 2000; 25(6): 861-85

24. Lloyd C, Joyce R, Hurry J, Ashton M. The effectiveness of primary school drug education. Drugs: Education, Prevention and Policy 2000; 7(2): 109-26

25. Mellanby A, Rees J, Tripp J. Peer-led and adult-led school health education: a critical review of available comparative research. Health Educ Res 2000; 15(5): 533-45

26. Parkin S, McKeganey N. The rise and rise of peer education approaches. Drugs: Education, Prevention and Policy 2000; 7(3): 293-310

27. Smyth NJ, Saulnier CF. Substance abuse prevention among high-risk youth. Journal of Prevention and Intervention in the Community 1996; 14(1/2): 61-79

28. Tobler NS, Roona MR, Ochshorn P, Marshall DG, Streke AV, Stackpole KM. School-based adolescent drug prevention programs: 1998 Meta-analysis. Journal of Primary Prevention 2000; 20: 275-336

29. White D, Pitts M. Educating young people about drugs: a systematic review. Addiction 1998; 93(10): 1475-87

30. Windle M, Windle RC. Adolescent tobacco, alcohol and drug use: current findings. Adolescent Medicine: State of the Art Reviews 1999; 10(1): 153-63

31. Canning U, Millward L, Raj T, Warm D. Drug use prevention among young people: a review of reviews. Evidence briefing. $1^{\text {st }}$ edition. London: Health Development Agency; 2004

32. McGrath Y, Sumnall H, McVeigh J, Bellis M. Drug use prevention among young people: a review of reviews. Evidence briefing update. London: National Institute for Health and Clinical Excellence; 2006

33. Cuijpers P. Effective ingredients of school-based drug prevention programs. A systematic review. Addict Behav 2002a; 27: 1009-23

34. Burkhart G, Crusellas L. Comparison of school-based prevention programmes in Europe. An analysis of the EDDRA (Exchange on drug demand reduction action) database. EMCDDA; 2002. Available at: 
http://eddrapdf.emcdda.org/EDDRA_analysis_school-based_prevention_2002.pdf. Accessed March 2, 2006

35. Cuijpers P. Zin en onzin van verslavingspreventie. Betekenis voor de praktijk (Prevention of addictions: sense or nonsense? Value for the practice) Verslaving 2005; 1(2): 3-16

36. Cuijpers P. Peer-led and adult-led school drug prevention: a meta-analytic comparison. J Drug Educ 2002b; 32(2): 107-19

37. Cuijpers P. Prevention of cannabis use and misuse. In: Spruit IP, editor. Cannabis 2002 Report Ministry of Public Health of Belgium. Technical Report of the International Scientific Conference. Brussels: Ministry of Public Health of Belgium; 2002c. p. 83-94

38. Pentz MA. Evidence-based prevention: characteristics, impact, and future direction. J Psychoactive Drugs 2003; 35(suppl)1: 143-53

39. Grimes DA, Schulz KF. An overview of clinical research: the lay of the land. Lancet 2002; 359: 57-61

40. Sackett DL, Haynes RB, Guyatt GH, Tugwell P. Clinical epidemiology. A basic science for clinical medicine. $2^{\text {nd }}$ edition. Boston: Little, Brown and Company; 1991

41. Sackett DL, Rosenberg WMC, Gray JAM, Haynes RB, Richardson WS. Evidence based medicine: what it is and what it isn't. Br Med J 1996; 312: 71-2

42. Hall W, Solowij N. Adverse effects of cannabis. Lancet 1998; 352: 1611-6

43. Channabasavanna SM, Paes M, Hall W. Mental and behavioral disorders due to cannabis use. In: Kalant H, Corrigall W, Hall W, Smart R, editors. The health effects of cannabis. Toronto: Centre for Addiction and Mental Health; 1999. p. 269-90

44. Hanak C, Tecco J, Verbanck P, Pelc I. Cannabis, mental health and dependence. In: Spruit IP, editor. Cannabis 2002 Report. Technical Report of the International Scientific Conference, Brussels: Ministry of Public Health of Belgium; 2002. p. 51-65

45. Kalant $\mathrm{H}$. Adverse effects of cannabis on health: an update of the literature since 1996. Progress in Neuro-Psychoparmacology and Biological Psychiatry 2004; 28: 849-63

46. Ramström J. Adverse health consequences of cannabis use. A survey of scientific studies published up to and including the Autumn of 2003. Sandviken: Sandvikens Tryckeri; 2004

47. Ramaekers JG, Berghaus G, van Laar M, Drummer OH. Performance impairment and risk of motor vehicle crashes after cannabis use. In: Spruit IP, editor. Cannabis 2002 Report. Technical Report of the International Scientific Conference. Brussels: Ministry of Public Health of Belgium; 2002. p. 66-82

48. Smiley A. Marijuana: on-road and driving-simulator studies In: Kalant H, Corrigall W, Hall W, Smart R, editors. The health effects of cannabis. Toronto: Centre for Addiction and Mental Health; 1999. p. 173-91

49. Laumon B, Gadegbeku B, Martin JL, Biecheler MB, the SAM Group. Cannabis intoxication and fatal road crashes in France: population based case-control study. Br Med J 2005; 331: 1371-7

50. Iversen I. Long-term effects of exposure to cannabis. Curr Opin Pharmacol 2005; 5: 69-72

51. Tashkin DP. Is frequent marijuana smoking harmful to health? West J Med 1993; 158: 635-7

52. Bergeret I, Papageorgiou C, Verbanck P, Pelc I. Cannabis and physical health. In: Spruit IP, editor. Cannabis 2002 Report. Technical Report of the International Scientific Conference. Brussels: Ministry of Public Health of Belgium; 2002. p. 44-50

53. King LA, Carpentier C, Griffiths P. An overview of cannabis potency in Europe. EMCDDA insights, 6. Lissabon: EMCDDA; 2004

54. Van Tichelt K, Canfyn M, Govaerts C, Lenearts K, Piette V, Parmentier F. $\Delta^{9}$-THC-concentraties in cannabis in 2003 en 2004. Project 'Samenstelling van drugs in omloop' in samenwerking met het Parket van Antwerpen (THC potency in cannabis in 2003 and 2004. Project composition of drugs in circulation in collaboration with the public prosecutor of Antwerp). FOD Volksgezondheid, Veiligheid van de Voedselketen en Leefmilieu. Brussel: Wetenschappelijk Instituut Volksgezondheid. Afdeling Geneesmiddelenanalyse; 2005

55. Schulz KF, Grimes DA. Case-control studies: research in reverse. Lancet 2002; 359: 431-4 
56. Fendrich M, Xu Y. The validity of drug use reports from juvenile arrestees. Int J Addict 1994; 29(8): 97185

57. Gadeyne S, Deboosere P. Socio-economische ongelijkheid in sterfte op middelbare leeftijd in België. Een analyse van de Nationale Databank Mortaliteit (Socio-economic inequality in mortality at middle age in Belgium. An analysis of the National Database Mortality). Brussel: VUB, Vakgroep Sociaal Onderzoek, Interface Demography; 2002

58. Dijker A, van Dongen M, Brug J. Evaluatie van gezondheidsvoorlichting (Evaluation of health educating). In: Brug J, Schaalma H, Kok G, Meertens RM, van der Molen HT, editors. Gezondheidsvoorlichting en gedragsverandering. Een planmatige aanpak (Health education and behaviour change. A systematic approach). Assen: Van Gorcum; 2000. p. 133-58

59. Schokkaert E, Van de Voorde C. Health care reform in Belgium. Health Econ 2005; 14(Suppl 1): S25-39 